\title{
Physicians' knowledge and continuing medical education regarding fitness to drive: a questionnaire-based survey in Southeast Switzerland
}

\author{
Matthias Pfäffli • Michael J. Thali • Sebastian Eggert
}

Received: 10 August 2011 / Accepted: 7 October 2011 /Published online: 20 October 2011

(C) Springer-Verlag 2011

\begin{abstract}
Valid information for physicians in Switzerland concerning knowledge and continuing education in traffic medicine is not available. Also, their attitude to the legally prescribed periodic driving fitness examinations is unclear. In order to gain more information about these topics, 635 resident physicians in Southeast Switzerland were sent a questionnaire (response rate 52\%). In a self-estimation, $79 \%$ of the queried physicians claimed to know the minimal medical requirements for drivers which are important in their specialty. Statistically significant differences existed between the specialties, whereby general practitioners most frequently claimed to know the minimal medical requirements $(90 \%)$. It appears that the minimal medical requirements for drivers are well known to the queried physicians. Fifty-two percent of the physicians favored an expansion of continuing education in traffic medicine. Such an expansion was desired to a lesser extent by physicians without knowledge of the minimal requirements $(p<0.001)$. A clear majority of the medical professionals adjudged the legally prescribed periodic driving fitness examinations as being an expedient means to identify unfit drivers. A
\end{abstract}

M. Pfäffli $(\bowtie)$

Department of Traffic Sciences, Institute of Forensic Medicine, University of Bern,

Bubenbergplatz $4 \mathrm{~b}$,

3001 Bern, Switzerland

e-mail: matthias.pfaeffli@irm.unibe.ch

\section{J. Thali}

Institute of Forensic Medicine, University of Zurich,

Winterthurerstrasse 190/52,

8057 Zurich, Switzerland

\section{S. Eggert}

Institute of Pathology and Forensic Medicine,

Cantonal Hospital of Grisons,

Loestrasse 170,

7000 Chur, Switzerland national standardized form for reporting potentially unfit drivers to the licensing authorities was supported by $68 \%$ of the responding physicians. Such a form could simplify and standardize the reports to the licensing authorities.

Keywords Fitness to drive $\cdot$ Continuing medical education · Driving $\cdot$ Traffic medicine $\cdot$ Survey $\cdot$ Medical requirements

\section{Introduction}

Substance abuse and physical diseases can have a relevant influence on driving fitness [1-4]. The identification of patients who are unfit to drive is an important contribution of physicians to traffic safety.

In Switzerland, every physician has the right to report a patient who is potentially unfit to drive to the licensing authorities without violating medical confidentiality [5]. In a questionnaire-based survey in Southeast Switzerland, the attitude of the physicians toward this reporting right and the actual frequency of the reporting was studied [6]. Ninetyseven percent of all physicians supported this right to report. On average, the physicians-for all specialties-reported 0.31 patients (standard deviation [SD] $0.64,95 \%$ confidence interval $[95 \% \mathrm{CI}] 0.24-0.38$ ) in the year before the survey and 1.00 patient (SD $1.74,95 \%$ CI $0.81-1.20$ ) in the past 5 years. The low number of reports per physician emphasizes clearly the importance and necessity of regular continuing education concerning traffic medicine.

Several studies have, however, shown an insufficient knowledge of medical professionals regarding the assessment of driving fitness and/or the associated existing legal regulations [7-13]. In this paper, the results of the abovementioned Swiss survey with regard to knowledge and continuing education in traffic medicine are shown. 
In Switzerland, the minimal medical requirements for drivers are specified in detail in an ordinance based on the Federal Act on Road Traffic. The requirements are divided into three groups (first group, bus drivers; second group, lorry/truck drivers and driving instructors; and third group, moped/motorcycle/tractor/car drivers; simplified) [14].

Furthermore, the attitude of physicians toward a new, national, standardized form for reporting and toward the legally prescribed periodic driving fitness examinations was queried. In Switzerland, drivers of the above-mentioned first and second groups must be subjected to such an examination every 5 years up to age 50, afterwards every 3 years. From age 70 on drivers of all three groups have to be examined in 2-year intervals [5]. These examinations are performed by physicians appointed by the licensing authorities. Commonly, these are general practitioners or internists.

\section{Material and methods}

Study design

Questionnaires were sent to all physicians with their own practice — independent of specialty — in Southeast Switzerland
(Swiss cantons Glarus, Graubünden, Schwyz and Uri) ( $n=$ 635). The questionnaires comprised 19 questions (six with demographic contents, 13 referring to traffic medicine issues). The detailed study design and the demographic characteristics are described in the first paper discussing the presented survey and will not be mentioned once again [6].

Data analysis

The data were analyzed using the SPSS Statistics 17.0 program for Windows (SPSS Inc., Chicago, USA). Answers from general practitioners, internists, and psychiatrists were evaluated separately while the other specialties, due to the small number, were subsumed under "other specialty".

For physicians with multiple specialties, the group assignment took place according to the following priorities:

1. Specialty "general medicine" and further certification (s): assigned to the "general medicine" group,

2. Specialty "internal medicine" and further certification (s): assigned to the "internal medicine" group, and

3. Multiple specialty certification(s), but without "general medicine" or "internal medicine": assigned to the "other specialty" group.

Table 1 Knowledge of minimal requirements/expansion of continuing education in traffic medicine

\begin{tabular}{|c|c|c|c|c|c|c|c|}
\hline & \multicolumn{3}{|c|}{ Minimal requirements known? } & \multicolumn{4}{|c|}{ Expand continuing education in traffic medicine? } \\
\hline & Yes, $\%(n)$ & No, $\%(n)$ & & Yes, \% $(n)$ & No, $\%(n)$ & No opinion, $\%(n)$ & \\
\hline Total & 79 (249) & $21(65)$ & & $52(163)$ & $34(107)$ & $14(43)$ & \\
\hline \multicolumn{8}{|l|}{ Sex } \\
\hline Male & $81(213)$ & $19(50)$ & \multirow[t]{2}{*}{$p=0.066$} & $51(133)$ & $37(96)$ & $12(32)$ & \multirow[t]{2}{*}{$p=0.034$} \\
\hline Female & $69(34)$ & $31(15)$ & & $58(29)$ & $20(10)$ & $22(11)$ & \\
\hline \multicolumn{8}{|l|}{ Age (in years) } \\
\hline$<35$ & $67(2)$ & $33(1)$ & \multirow[t]{5}{*}{$p=0.326$} & $67(2)$ & $33(1)$ & $0(0)$ & \multirow[t]{5}{*}{$p=0.787$} \\
\hline $36-45$ & $73(49)$ & $27(18)$ & & $53(36)$ & $31(21)$ & $16(11)$ & \\
\hline $46-55$ & $81(96)$ & $19(23)$ & & $56(66)$ & $33(38)$ & $11(13)$ & \\
\hline $56-65$ & $84(88)$ & $16(17)$ & & $45(48)$ & $39(41)$ & $16(17)$ & \\
\hline$>65$ & $68(13)$ & $32(6)$ & & $61(11)$ & $28(5)$ & $11(2)$ & \\
\hline \multicolumn{8}{|l|}{ Years in practice } \\
\hline$<10$ & $77(75)$ & $23(22)$ & \multirow[t]{4}{*}{$p=0.512$} & $61(59)$ & $29(28)$ & $10(10)$ & \multirow[t]{4}{*}{$p=0.395$} \\
\hline $11-20$ & $77(75)$ & $23(23)$ & & $51(49)$ & $35(34)$ & $14(14)$ & \\
\hline $21-30$ & $84(81)$ & $16(15)$ & & $44(43)$ & $40(39)$ & $16(15)$ & \\
\hline$>30$ & $76(16)$ & $24(5)$ & & $60(12)$ & $25(5)$ & $15(3)$ & \\
\hline \multicolumn{8}{|c|}{ Minimal requirements known? } \\
\hline Yes & - & - & & $68(44)$ & $15(10)$ & $17(11)$ & \multirow[t]{2}{*}{$p=0.001$} \\
\hline No & - & - & & 48 (117) & $39(97)$ & $13(31)$ & \\
\hline \multicolumn{8}{|l|}{ Specialty } \\
\hline General practitioner & $90(120)$ & $10(14)$ & \multirow[t]{4}{*}{$p<0.001$} & $44(58)$ & $45(60)$ & $11(15)$ & \multirow[t]{4}{*}{$p<0.001$} \\
\hline Internal medicine & $85(40)$ & $15(7)$ & & $53(25)$ & $38(18)$ & $9(4)$ & \\
\hline Psychiatry & 79 (22) & $21(6)$ & & 85 (23) & $11(3)$ & $4(1)$ & \\
\hline Other & $64(67)$ & $36(38)$ & & $54(57)$ & 34 (107) & $22(23)$ & \\
\hline
\end{tabular}


Table 2 Periodic driving fitness examination/new national standardized form for reporting

\begin{tabular}{|c|c|c|c|c|c|c|c|c|}
\hline & \multicolumn{4}{|c|}{$\begin{array}{l}\text { Periodic driving fitness examination an expedient means } \\
\text { for identifying unfit drivers? }\end{array}$} & \multicolumn{4}{|c|}{ New national standardized form for reporting? } \\
\hline & Yes, \% $(n)$ & No, \% $(n)$ & No opinion, \% $(n)$ & & Yes, \% $(n)$ & No, $\%(n)$ & No opinion, $\%(n)$ & \\
\hline Total & $74(232)$ & $18(56)$ & $8(27)$ & & $68(217)$ & $28(88)$ & $4(12)$ & \\
\hline \multicolumn{9}{|l|}{ Sex } \\
\hline Male & 75 (197) & 17 (44) & $8(22)$ & \multirow[t]{2}{*}{$p=0.402$} & 66 (174) & $31(83)$ & $3(8)$ & \multirow[t]{2}{*}{$p=0.001$} \\
\hline Female & $66(33)$ & $24(12)$ & $10(5)$ & & $84(42)$ & $8(4)$ & $8(4)$ & \\
\hline \multicolumn{9}{|l|}{ Age (in years) } \\
\hline$<35$ & $67(2)$ & $0(0)$ & $33(1)$ & \multirow[t]{5}{*}{$p=0.440$} & $100(3)$ & $0(0)$ & $0(0)$ & \multirow[t]{5}{*}{$p=0.658$} \\
\hline $36-45$ & $66(45)$ & $27(18)$ & $7(5)$ & & $75(51)$ & $21(14)$ & $4(3)$ & \\
\hline $46-55$ & $77(90)$ & $14(16)$ & $9(11)$ & & $69(82)$ & $27(32)$ & $4(5)$ & \\
\hline $56-65$ & $74(79)$ & $18(19)$ & $8(9)$ & & $62(67)$ & $34(36)$ & $4(4)$ & \\
\hline$>65$ & $79(15)$ & $16(3)$ & $5(1)$ & & $68(13)$ & $32(6)$ & $0(0)$ & \\
\hline \multicolumn{9}{|l|}{ Years in practice } \\
\hline$<10$ & $68(67)$ & $20(19)$ & $12(12)$ & \multirow[t]{4}{*}{$p=0.263$} & $78(76)$ & $18(18)$ & $4(4)$ & \multirow[t]{4}{*}{$p=0.259$} \\
\hline $11-20$ & $71(68)$ & $18(17)$ & $11(11)$ & & $65(64)$ & $31(30)$ & $4(4)$ & \\
\hline $21-30$ & $81(79)$ & $16(16)$ & $3(3)$ & & $63(62)$ & $33(32)$ & $4(4)$ & \\
\hline$>30$ & $76(16)$ & $19(4)$ & $5(1)$ & & $62(13)$ & $38(8)$ & $0(0)$ & \\
\hline \multicolumn{9}{|c|}{ Minimum requirements known } \\
\hline Yes & 77 (189) & $15(38)$ & $8(20)$ & \multirow[t]{2}{*}{$p=0.108$} & $80(52)$ & $15(10)$ & $5(3)$ & \multirow[t]{2}{*}{$p=0.038$} \\
\hline No & $65(42)$ & $26(17)$ & $9(6)$ & & $66(163)$ & $31(78)$ & $3(8)$ & \\
\hline \multicolumn{9}{|l|}{ Specialty } \\
\hline General practitioner & 79 (106) & $19(26)$ & $2(3)$ & \multirow[t]{4}{*}{$p=0.001$} & $57(77)$ & $39(53)$ & $4(6)$ & \multirow[t]{4}{*}{$p=0.002$} \\
\hline Internal medicine & $79(37)$ & $19(9)$ & $2(1)$ & & $75(35)$ & $25(12)$ & $0(0)$ & \\
\hline Psychiatry & $62(17)$ & $19(5)$ & $19(5)$ & & $79(22)$ & $21(6)$ & $0(0)$ & \\
\hline Other & $68(72)$ & $15(16)$ & $17(18)$ & & $78(83)$ & $16(17)$ & $6(6)$ & \\
\hline
\end{tabular}

The answers to the questions "minimal requirements known?", "expand continuing education in traffic medicine?", "periodic driving fitness examination an expedient means for identifying unfit drivers?", and "new national standardized form for reporting?" (Tables 1 and 2) were analyzed using exploratory data analysis. The comparison of nominal- and ordinal-scaled variables was performed using the Chisquared test. To find out which class significantly contributed to a significant Chi-squared statistics, standardized residuals $(R)$ were calculated. The level for statistical
Fig. 1 Sources of traffic medicine informations. Multiple answers possible

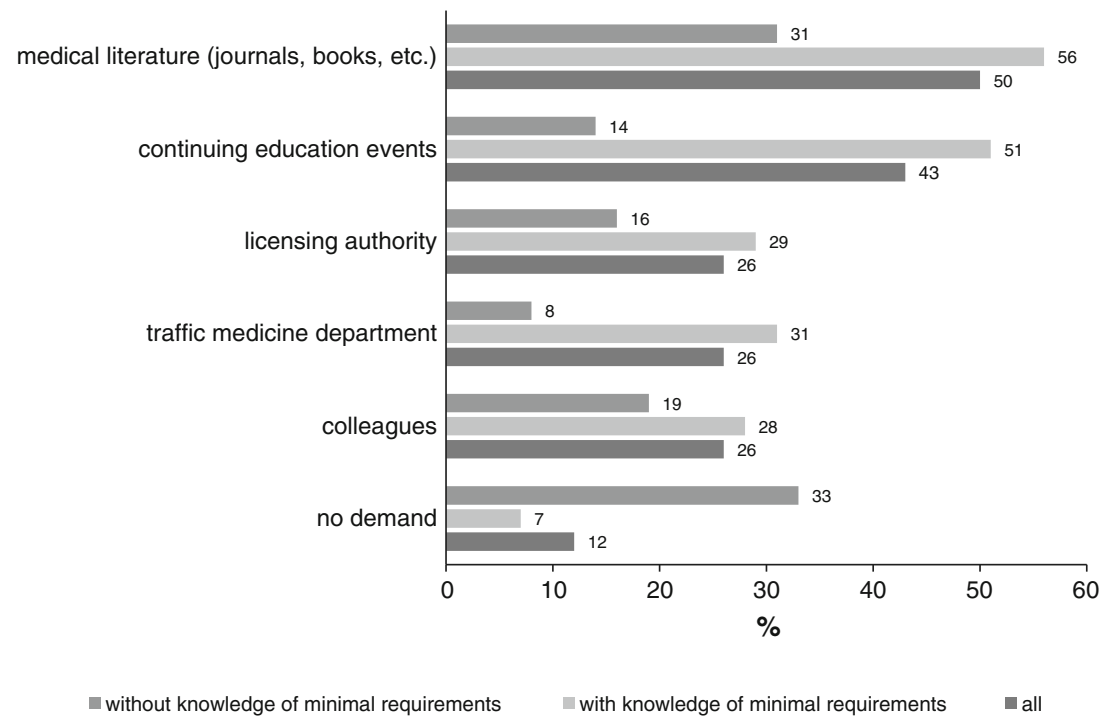


significance was set to $p<0.0026$ (with Bonferroni correction for multiple comparisons, without correction $p<0.05$ ). The results shown in Fig. 1 were obtained by using descriptive data analysis.

\section{Results}

The response rate amounted to $52 \%$ (50\% if returned nonfilled-out questionnaires are excluded). According to their self-estimation, the existing minimal medical requirements in their own specialty (e.g., regulations concerning visual acuity for ophthalmologists) were known to $79 \%$ of the responding physicians. Statistically significant differences existed among the individual specialties $(p<0.001)$. The calculated standardized $R$ showed that this difference is based on the very low number of the general practitioners without knowledge of the minimal requirements $(R=-2.6)$ and the large number of physicians in the category "other specialties" without such knowledge $(R=3.5)$. For sex and categories of age and years in practice, there were no relevant differences (Table 1).

Fifty-two percent of the physicians voted for an expansion of continuing education in traffic medicine. Physicians without knowledge of minimal requirements were less often in favor of an expansion than those with knowledge ( $48 \%$ and $68 \%$, respectively). Statistically significant differences existed among the specialties $(p<0.001)$ : These were due to the large number of general practitioners $(R=2.2)$ who did not wish an expansion of the continuing education and psychiatrists $(R=$ 2.4) who supported it. An above-average portion of physicians in the category "other specialties" had no opinion in this regard $(22 \%$, in comparison to general practitioners, for example, $11 \%$, Table 1).

Fifty percent and $43 \%$ of the responding physicians gained their information on traffic medicine from the medical literature and continuing education events, respectively. Only one fourth of those queried already approached a specialized traffic medicine department (Fig. 1). There were conspicuous differences between physicians with and without knowledge of the minimal medical requirements: All the information sources cited in the questionnaire were utilized distinctly more often by physicians with knowledge of the minimal requirements than those without such knowledge. Examples are as follows: medical literature (56\% as opposed to $31 \%$ ), continuing education events (51\% as opposed to $14 \%$ ), and specialized traffic medicine departments ( $31 \%$ as opposed to $8 \%$ ). The physicians without knowledge of the minimal medical requirements also claimed, more frequently than average, to have no need for traffic medicine information (33\% as opposed to $7 \%$, see Fig. 1).

The great majority of the physicians (74\%) estimated the currently performed periodic driving fitness assessments to be sufficient to identify potentially unfit drivers. In this regard, no differences existed between the sexes, the categories of age and years in practice, and the knowledge of the minimal requirements. Significant differences, though, were present among the specialties $(p=0.001)$. This may be explained by the low and high number of the general practitioners and those of other specialties who had no opinion about the periodic driving fitness examinations ( $R=-2.5$ and $R=3$, respectively).

Sixty-eight percent of all queried physicians advocated the creation of a new national, standardized form for reporting potentially unfit drivers to the licensing authorities. Female physicians supported such a form distinctly more frequently than male physicians $(p=0.001)$. Physicians without knowledge of the minimal medical requirements considered such a standardized form as being desirable distinctly less often, but this has no statistical significant difference $(p=0.038)$.

Concerning a national, standardized form, there were significant differences among the specialties $(p=0.002)$. This was due to the high number of general practitioners who opposed a standardized form $(R=2.5)$ and the low number of physicians of "other specialties" who endorsed it $(R=-2.3)$.

\section{Discussion}

Barely $80 \%$ of all physicians claimed to know the current Swiss minimal medical requirements for drivers. Roughly, the same proportion was found in a Canadian study: depending on the province, between $14.6 \%$ and $29.3 \%$ of the psychiatrists did not know the legal regulations [15]. Portions in this magnitude, though, are to be understood with caution: in several investigations, when specific questions were asked, the portion of correct answers was distinctly lower. In an Australian study, for example, only $21.6 \%$ of the queried physicians provided right answers to six questions concerning concrete traffic medicine problems [9]. For questions concerning driving fitness in specific somatic illnesses, Marshall et al. obtained correct answers ranging from $11.6 \%$ to $89.8 \%$ [7]. In the first paper concerning the presented survey, the only significant factor with influence on the knowledge of minimal requirements was the specialty "general medicine" (logistic regression, odds ratio 4.6, $p<0.0001$ ) [6].

The importance of communicating structured traffic medicine knowledge was shown by Byszewski et al.: knowledge and confidence in the communicated traffic medicine issue increased significantly after Canadian primary health care workers were provided with a booklet dealing with driving and dementia ("driving and dementia toolkit") [16]. The influence of continuing education is well shown in the presented survey: all queried sources for 
traffic medicine information were used distinctly less often by physicians who were not aware of the minimal medical requirements.

Fifty-two percent of all the responding physicians quoted for an expansion of continuing education in traffic medicine. In comparison, this proportion is rather low: in the literature, one finds approval rates of $83 \%$ to $97 \%[7,15,17]$. Only half of the responding physicians feel a need for traffic medicine continuing education. This result cannot only be explained by the fact that physicians were also queried in whose specialties driving fitness problems have little or no importance, such as pediatricians and gynecologists, for example. General practitioners also exhibited a low approval quota of merely $44 \%$. General practitioners are often responsible for the coordination of patient care by specialists (case management) in Switzerland. Therefore, it must be an inadequate awareness of traffic medicine problems. Not explainable is the finding that, on one hand, $48 \%$ of the physicians without knowledge of the minimal requirements desire an expansion of the continuing education in traffic medicine issues, on the other hand, these same physiciansdistinctly more frequently than their colleagues with knowledge of the minimal requirements - stated that they have no need for traffic medicine information. This surprising fact should be object of further investigations.

For the responding physicians, the medical literature $(50 \%)$ and continuing education events $(43 \%)$ were key resources for information about traffic medicine topics. In a Canadian study, the most frequent choiced forms of continuing medical education were comparable to these results: conference presentations $49.4 \%$, workshops $47.4 \%$, and journal articles (46.4\%) [7].

In order to improve traffic medicine knowledge, these preferred resources should be used systematically for its communication. Also, with the aim of supporting continuing education in traffic medicine, the Swiss Society of Legal Medicine established a traffic medicine section in 2010 [18].

Traffic medicine departments were named as a source for specialized information by only $26 \%$ of the queried physicians. An active communication and an approach toward practicing physicians are therefore imperative for the traffic medicine departments to justify their intended role as "opinion leaders".

Almost three fourth of the physicians said they considered the statutory periodic driving fitness assessment to be suitable for identifying patients that are unfit to drive a vehicle. The number of psychiatrists and physicians of the group "other specialties" who had no opinion concerning this issue was conspicuously high. A possible explication is the fact that these specialties never or very seldom perform such periodic driving fitness examinations. In Switzerland, it is mostly general practitioners and internists that are given this responsibility.

In all the examined groups, a majority approved of the creation of a national standardized form for reporting potentially unfit drivers. Interestingly, the approval among the general practitioners-frequently concerned with traffic medicine problems, as already mentioned - was the lowest. General practitioners may have most experience in reporting unfit drivers and so do not have the same need for a standardized form as less experienced physicians of other specialties. In our opinion, a national reporting form would simplify and standardize the reporting procedure. An increased frequency of reporting could be expected.

The response rate amounted to $52 \%$. In comparison to the survey population, male physicians and general practitioners were overrepresented while the "other specialty" group was underrepresented (male physicians, $84 \%$ of respondents compared to $80 \%$ in survey population; general practitioners, $43 \%$ compared to $35 \%$; and "other specialty", $33 \%$ compared to $43 \%$ ).

This distribution of demographic groups between the respondents and the survey population can cause skews in our results. But in our opinion, these skews do not influence the results in a crucial way.

The present investigation does not claim to be representative for all of Switzerland. Nevertheless, due to the high response rate, the survey can be considered to be representative for the investigated, somewhat rural and small town areas. In terms of Switzerland, a tendency estimate can be cautiously deduced from the investigation results. The response rate of our study is discussed in contrast with similar studies in the first paper dealing with the presented survey [6].

\section{Conclusions}

According to the self-estimation of the respondent physicians, the Swiss minimal medical requirements for drivers are well known. Nevertheless, a slight majority of the queried physicians advocated an expansion of continuing education in traffic medicine. This should take place primarily via medical literature (journals, books, etc.) and educational events, since these are said to be the most widely used forms of continuing education.

A large majority consider the legally prescribed periodic driving fitness examinations as a proven means for identifying those unfit to drive. A new national standardized form for reporting potentially unfit drivers was greeted by medical professionals as a way to simplify their work.

\section{References}

1. Galski T, Vocaturo L, Galski TM (2009) Driving, medical illness, and medications. In: Schultheis MT, DeLuca J, Chute DL (eds) Handbook for the assessment of driving capacity, 1st edn. Elsevier, San Diego, pp 160-168 
2. Penning R, Veldstra JL, Daamen AP, Olivier B, Verster JC (2010) Drugs of abuse, driving and traffic safety. Curr Drug Abuse Rev 3 (1):23-32

3. Aschkenasy MT, Drescher MJ, Ratzan RM (2006) Physician reporting of medically impaired drivers. J Emerg Med 30(1):2939

4. Marshall SC, Man-Son Hing M (2011) Multiple chronic medical conditions and associated driving risk: a systematic review. Traffic Inj Prev 12:142-148

5. Federal Act of 19 Decemeber 1958 on Road Traffic (Strassenverkehrsgesetz). The Federal Authorities of the Swiss Confederation. http://www.admin.ch/ch/d/sr/741_01/index.html. Accessed 20 July 2011

6. Eggert S, Thali MJ, Pfäffli M (2011) Discretionary medical reporting of potentially unfit drivers: a questionnaire-based survey in Southeast Switzerland. Int J Legal Med. doi:10.1007/s00414011-0574-5

7. Marshall SC, Gilbert N (1999) Saskatchewan physicians' attitudes and knowledge regarding assessment of medical fitness to drive. CMAJ 160(12):1701-1704

8. King D, Benbow SJ, Barrett JA (1992) The law and medical fitness to drive - a study of doctors' knowledge. Postgrad Med J 68:624-628

9. Shanahan EM, Sladek RM, Phillips P (2007) Medical aspects of fitness to drive. What do public hospital doctors know and think? Intern Med J 37:372-376

10. Kelly R, Warke T, Steele I (1999) Medical restrictions to driving: the awareness of patients and doctors. Postgrad Med J 75:537-539
11. Lipski PS (2002) A survey of general practitioners' attitudes to older drivers on the New South Wales Coast. Australas J Ageing 21(2):98-100

12. Steier TS, Kitai E, Wiener A, Kahan E (2003) Are medical reports on fitness to drive trustworthy? Postgrad Med J 79:52-54

13. Fisher BM, Storer AM, Frier BM (1985) Diabetes, driving, and the general practitioner. Br Med J (Clin Res Ed) 291:181-182

14. Ordinance of 27 October 1976 on the Admission of Persons and Vehicles to Road Traffic (Verkehrszulassungsverordnung). The Federal Authorities of the Swiss Confederation. http://www. admin.ch/ch/d/sr/c741_51.html. Accessed 20 July 2011

15. Ménard I, Korner-Bitensky N, Dobbs B, Casacalenda N, Beck PR, Dippsych CM, Gélinas I, Molnar FJ, Naglie G (2006) Canadian psychiatrists' current attitudes, practices, and knowledge regarding fitness to drive in individuals with mental illness: a cross-Canada survey. Can J Psychiatry 51(13):836-846

16. Byszewski AM, Graham ID, Amos S, Man-Son-Hing M, Dalziel WB, Marshall S, Hunt L, Bush C, Guzman D (2003) A continuing medical education initiative for Canadian primary care physicians: the driving and dementia toolkit: a pre- and postevaluation of knowledge, confidence gained, and satisfaction. J Am Geriatr Soc 51:1484-1489

17. Jang RW, Man-Son-Hing M, Molnar FJ, Hogan DB, Marshall SC, Auger J, Graham ID, Korner-Bitensky N, Tomlinson G, Kowgier ME, Naglie G (2007) Family physicians' attitudes and practices regarding assessments of medical fitness to drive in older persons. J Gen Intern Med 22(4):531-543

18. Traffic Medicine. Swiss Society of Legal Medicine. www. sgrm.ch/verkehrsmedizin/ueber-die-sektion.html. Accessesd 20 July 2011 